\title{
Helical and kinase domain mutations of PIK3CA, and their association with hormone receptor expression in breast cancer
}

\author{
CHITTIBABU VATTE ${ }^{1,2}$, ALI MOHAMMED AL AMRI ${ }^{3}$, CYRIL CYRUS $^{1,2}$, SHAHANAS CHATHOTH $^{1,2}$, \\ AHMED ALSAYYAH $^{4}$, ARAFAT AHMAD ${ }^{1}$, MOHAMMED SHAKIL AKHTAR ${ }^{1}$, NADA FEHAID ALRASHIDI ${ }^{3}$, \\ NITHYA JAYASEELI ${ }^{3}$, HAMED AL WADANI ${ }^{5,6}$, ALHUSSAIN AL ZAHRANI ${ }^{7}$ and AMEIN KADHEM AL ALI ${ }^{1,6}$ \\ ${ }^{1}$ Department of Biochemistry, College of Medicine; ${ }^{2}$ Department of Genetic Research, Institute for Research and \\ Medical Consultations, Imam Abdulrahman Bin Faisal University, Dammam 31441; Departments of \\ ${ }^{3}$ Internal Medicine and ${ }^{4}$ Pathology, King Fahd Hospital of The University, Imam Abdulrahman Bin Faisal University, \\ Al-Khobar 31952; ${ }^{5}$ Department of Surgery; ${ }^{6}$ College of Medicine, King Faisal University, \\ Hofuf, Al-Ahsa 31982; ${ }^{7}$ Department of Clinical Laboratories Sciences, College of Applied Medical Sciences,
} King Saud University, Riyadh 11362, Kingdom of Saudi Arabia

Received February 4, 2018; Accepted January 31, 2019

DOI: $10.3892 / \mathrm{ol} .2019 .10565$

\begin{abstract}
Breast cancer is one of the major causes of female morbidity and mortality, accounting for $\sim 25 \%$ of the total cancer cases in women. Phosphatidylinositol-4,5-bisphosphate 3-kinase catalytic $\alpha$ subunit (PIK3CA) mutations serve a major role in downstream signaling of receptor tyrosine kinases. The present study aimed to elucidate the frequency of exon 9 and 20 mutations of PIK3CA and their role in disease progression. A total of 118 tumor samples from confirmed breast cancer patients were collected from the histopathology laboratory at King Fahd Hospital of the University (Al-Khobar, Saudi Arabia). Sanger sequencing was performed on extracted DNA to identify the mutations on exons 9 and 20 of PIK3CA. The results were further validated by competitive allele-specific TaqMan polymerase chain reaction. Three mutations, namely E542K and E545K within exon 9, and H1047R within exon 20 , were observed in 25 patients $(21.2 \%)$. Among these, 18 patients carried the H1047R mutation of the kinase domain, while the remaining 7 patients carried mutations in the helical domain. PIK3CA mutations were associated with the estrogen receptor-positive/progesterone receptor-positive $\left(\mathrm{ER}^{+} / \mathrm{PR}^{+}\right)$ group of tumors in contrast to the $\mathrm{ER}^{-} / \mathrm{PR}^{-}$group $(\mathrm{P}=0.021)$. Furthermore, it was observed that the PIK3CA mutation was associated with a poor disease prognosis. Taken together, the current study emphasized the potential of PIK3CA mutations
\end{abstract}

Correspondence to: Dr Chittibabu Vatte, Department of Biochemistry, College of Medicine, Imam Abdulrahman Bin Faisal University, King Faisal Road, Dammam 31441, Kingdom of Saudi Arabia

E-mail: cbvatte@iau.edu.sa

Key words: somatic mutation, hormone receptor, prognosis, target therapy, sequencing as an important biomarker for breast cancer classification and the possible use of $P I K 3 C A$ inhibitor as targeted therapy for breast cancer.

\section{Introduction}

Breast cancer is the most frequently diagnosed cancer in women, accounting for $\sim 25 \%$ of the total number of cancer cases, and is one of the leading causes of female mortalities worldwide (1). Breast cancer is categorized based on clinicopathological features and molecular signatures. Estrogen receptor (ER), progesterone receptor (PR) and human epidermal growth factor receptor 2 (HER2) serve as key biomarkers in breast cancer, and their expression in tumor cells forms the basis for endocrine therapy, targeted therapy and disease prognosis.

Phosphatidylinositol-4,5-bisphosphate 3-kinase catalytic subunit $\alpha$ (PIK3CA), which is located on chromosome $3 q 26.32$, encodes the catalytic subunit p110 $\alpha$ of class IA phosphoinositide 3-kinase (PI3K). PIK3CA is one of the most commonly mutated oncogenes in several types of human cancer, including breast, colon and endometrial cancer (2). It serves a major role in downstream signaling of receptor tyrosine kinases (RTKs), and is therefore critical in the regulation of cell proliferation, growth, differentiation, migration and survival $(2,3)$. In 2004, somatic mutations in the PIK3CA gene were reported for the first time in solid tumors (3). Although the role of $P I K 3 C A$ mutations in diagnosis and disease progression has been studied extensively (4-15), there is no consensus on the use of PIK3CA as a biomarker.

A previous study by Samuels et al (3) reported that the frequency of PIK3CA mutations in breast cancer was $8 \%$, while further studies revealed that approximately $21-34 \%$ of breast cancer cases presented PIK3CA mutations $(2,16,17)$. It has been reported that $P I K 3 C A$ somatic mutations are clustered within exons 9 and 20, which correspond to the helical and kinase domains, respectively $(2,18,19)$, and are 
gain-of-function mutations with a transforming capacity (20). In addition, mutations in exon 9 (helical domain) are resistant to the inhibitory effect of p85 through Src-homology 2 domain. A higher level of mutations in the kinase domain $(14.6 \%)$ compared with the helical domain was reported in a large cohort with predominantly lymph node-positive breast cancer (21).

Among Saudi women with cancer, the incidence of breast cancer ranges between 18 and $34.8 \%$, with the lowest frequency observed in the southwestern region $(18 \%)$ and the highest frequency in the eastern region $(34.8 \%)$. The highest incidence of breast cancer was observed in women aged between 30-44 years (22). Therefore, the objective of the present study was to evaluate the PIK3CA hotspot mutations in breast cancer patients in Saudi Arabia and in subsets of breast cancer cases based on hormone receptor expression.

\section{Materials and methods}

Study population and histopathology. This retrospective study included a total of 118 breast tumor samples from 118 women who were histopathologically diagnosed with breast cancer (23) at King Fahd Hospital of the University (Al-Khobar, Saudi Arabia). The inclusion criteria were: i) Confirmed breast cancer diagnosis by histopathology analysis; and ii) patient age, 18-80 years. The tumor samples were collected between May 2005 and February 2014, and the mean age of the patients was $50.26 \pm 11.36$ years. All patients were from the eastern province of Saudi Arabia. The formalin-fixed paraffin-embedded (FFPE) tissue specimens were subjected to hematoxylin and eosin staining to examine the tumor cell content and reconfirm the diagnosis. FFPE specimens containing $>70 \%$ of tumor cells were selected for further analysis. The clinicopathological parameters and expression pattern of ER, PR and HER2 determined by immunohistochemistry were obtained from the medical records of the patients. Patient outcome was estimated according to the status of 12 parameters, including local recurrence, absence of ER and PR expression, grade 3 tumor, stage III and IV tumors, Ki67 expression (>50\%), lymph node positivity, visceral metastasis, lympho-vascular invasion, age ( $<50$ years), tumor size $(>5 \mathrm{~cm})$ and HER 2 positivity. The prognosis of patients exhibiting $\geq 8$ of the aforementioned characteristics was considered to be poor, while patients with $<8$ of these characteristics were considered to have good prognosis. Based on the ER, PR and HER2 expression pattern of the tumor tissues the patient cohort was divided into 26 groups, including the $\mathrm{ER}^{+}, \mathrm{ER}^{-}, \mathrm{PR}^{+}, \mathrm{PR}^{-}, \mathrm{HER} 2^{+}, \mathrm{HER} 2^{-}$, $\mathrm{ER}^{-} \mathrm{PR}-\mathrm{ER}^{+} \mathrm{PR}^{+}, \mathrm{ER}^{-} \mathrm{PR}^{+}, \mathrm{ER}^{+} \mathrm{PR}^{-}, \mathrm{ER}^{-} \mathrm{HER} 2^{-}, \mathrm{ER}^{+} \mathrm{HER}^{+}$, ER ${ }^{-H E R} 2^{+}, \mathrm{ER}^{+} \mathrm{HER} 2^{-}, \mathrm{PR}^{-} \mathrm{HER} 2^{-}, \mathrm{PR}^{+} \mathrm{HER} 2^{+}, \mathrm{PR}^{-} \mathrm{HER} 2^{+}$, PR $^{+}$HER2-, ER-PR-HER2-, ER-PR ${ }^{+}$HER2-, ER ${ }^{+}$PR $^{+}$HER2-, $\mathrm{ER}^{+} \mathrm{PR}^{+} \mathrm{HER}^{+}, \mathrm{ER}^{+} \mathrm{PR}^{-} \mathrm{HER} 2^{+}, \mathrm{ER}^{+} \mathrm{PR}^{-} \mathrm{HER} 2^{-}, \mathrm{ER}^{-} \mathrm{PR}^{-} \mathrm{HER} 2^{+}$ and $\mathrm{ER}^{-} \mathrm{PR}{ }^{+} \mathrm{HER} 2^{+}$groups.

The current study was approved by the Institutional Review Board of Imam Abdulrahman Bin Faisal University (approval no. IRB-2014-01-007; Dammam, Saudi Arabia). Written informed consent was obtained from patients for the use of FFPE specimens for research purposes.

Detection of PIK3CA mutations by direct sequencing. The FFPE tissue specimens were subjected to microtomy to obtain $5-\mu \mathrm{m}$ sections. Six sections from each specimen were utilized for DNA isolation using the QIAmp DNA FFPE tissue kit (Qiagen GmbH, Hilden, Germany) as per the manufacturer's protocol. The purified DNA was checked for DNA quantity and quality by Nanodrop spectrophotometer (Thermo Fisher Scientific, Inc., Waltham, MA, USA). Mutations in exons 9 and 20 of PIK3CA were detected by polymerase chain reaction (PCR) in a total volume of $25.0 \mu \mathrm{l}$, containing 1.25 U GoTaq polymerase (Promega Corporation, Madison, WI, USA), $0.2 \mathrm{mM}$ of each dNTP, $1.5 \mathrm{mM} \mathrm{MgCl}_{2}$, $1 \mathrm{X}$ Taq buffer, $20 \mathrm{pM}$ of each primer (exon 9 forward, 5'-CCAGAGGGGAAAAATATGACA-3'; exon 9 reverse, 5'-CATTTTAGCACTTACCTGTGAC-3'; exon 20 forward, 5'-CATTTGCTCCAAACTGACCA-3'; and exon 20 reverse, 5'-TGAGCTTTCATTTTCTCAGTTATCTTTTC-3') and $50 \mathrm{ng}$ DNA. The thermocycling conditions were as follows: 1 cycle of $5 \mathrm{~min}$ at $95^{\circ} \mathrm{C} ; 40$ cycles of $30 \mathrm{sec}$ at $95^{\circ} \mathrm{C}, 30 \mathrm{sec}$ at $54^{\circ} \mathrm{C}$, and $30 \mathrm{sec}$ at $72^{\circ} \mathrm{C}$; and 1 cycle of $5 \mathrm{~min}$ at $72^{\circ} \mathrm{C}$. Subsequently, the PCR products were analyzed on a $2 \%$ agarose gel, which indicated the expected amplicon for exon 9 of $195 \mathrm{bp}$ and for exon 20 of $338 \mathrm{bp}$ (24). The sequence analysis was performed using the CodonCode aligner software (CodonCode Corporation, Centerville, MA, USA). The NG_012113.2 sequence (National Center for Biotechnology Information, Bethesda, MD, USA) was used as a reference sequence. The helical and kinase mutations E542K, E545K and H1047R are represented in Fig. 1.

Detection of PIK3CA mutations by competitive allele-specific TaqMan (CAST) PCR. The mutation results were confirmed using CAST PCR technology with the ABI 7500 Real-time PCR thermocycler (Thermo Fisher Scientific, Inc.). A total of three TaqMan mutation detection assays (Thermo Fisher Scientific, Inc.) for E542K (assay ID, Hs00000822_mu; cat. no. 4465804), E545K (assay ID, Hs00000824_mu; cat. no. 4465804) and H1047R (assay ID, Hs00000831_mu; cat. no. 4465804) were performed using quantitative PCR as per the manufacturer's protocol. Briefly, 1X TaqMan genotyping master mix, locus specific TaqMan FAM dye labeled mutation assay and $50 \mathrm{ng}$ DNA were mixed, made up to $20 \mu \mathrm{l}$ final volume in a 96-well plate, and subjected to quantitative PCR on the ABI7500 Real-time PCR system using the following thermocycling conditions: $95^{\circ} \mathrm{C}$ for $10 \mathrm{~min}$, followed by five cycles at $92^{\circ} \mathrm{C}$ for $15 \mathrm{sec}$ and $58^{\circ} \mathrm{C}$ for $1 \mathrm{~min}$, and forty cycles at $92^{\circ} \mathrm{C}$ for $15 \mathrm{sec}$ and $60^{\circ} \mathrm{C}$ for 1 min. Simultaneously, reference PIK3CA was amplified using a reference assay probe. Mutation Detector ${ }^{\mathrm{TM}}$ software (version 2.0; Thermo Fisher Scientific, Inc.) was used to classify the mutation status. The tumor samples that did not exhibit these three mutations were used as negative control samples in CAST PCR.

Statistical analysis. The frequency of each mutation was confirmed by direct counting. Fisher's exact test was used to determine the significance of the association among the groups. A statistically significant difference was determined if the P-value was <0.05. SPSS version 19 (IBM Corp., Armonk, NY, USA) software was used to perform the Fisher's exact test. Survival analysis was performed using Kaplan-Meier curve analysis and log-rank test. 


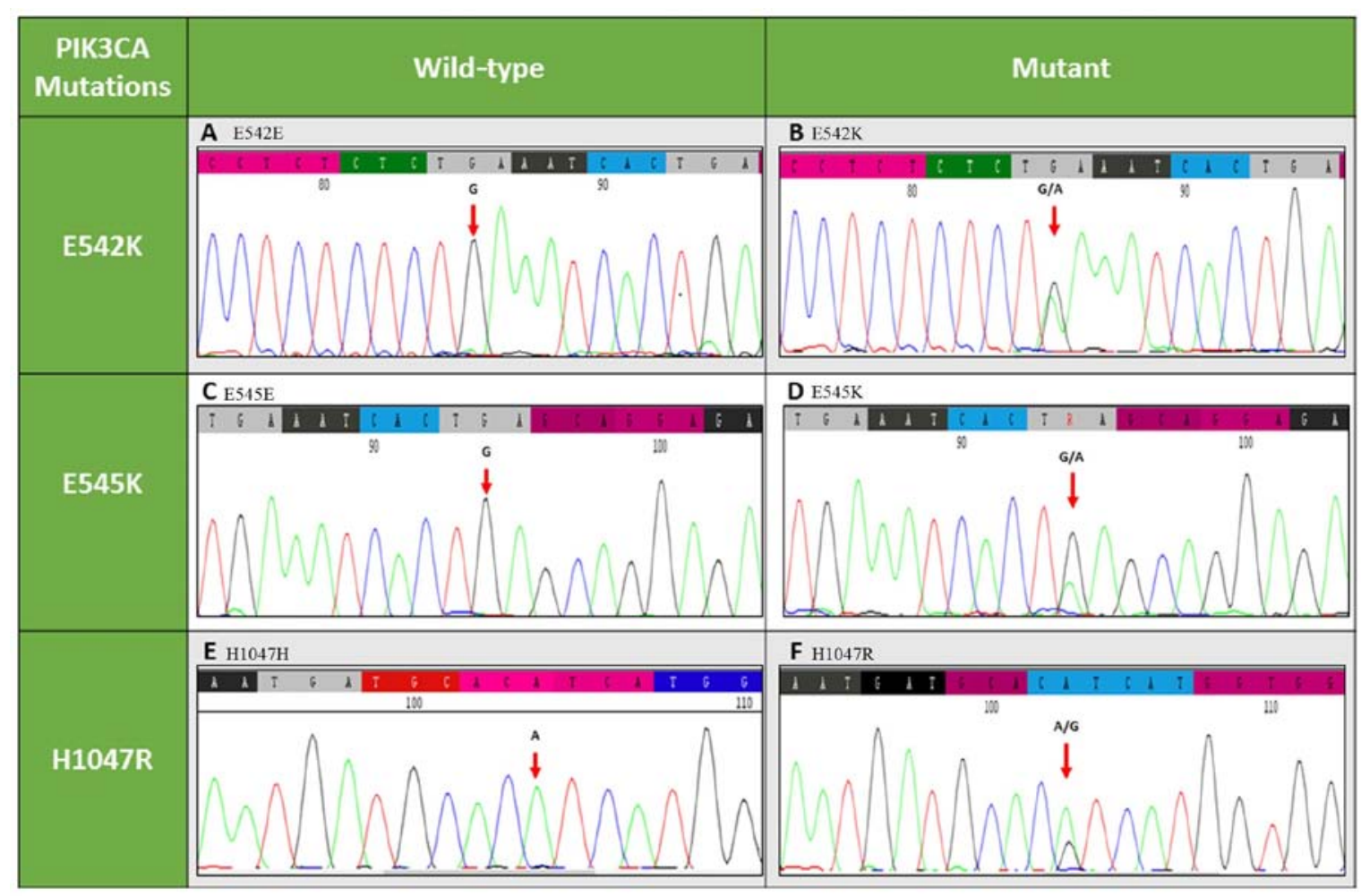

Figure 1. Representative electropherograms of exons 9 and 20 of PIK3CA gene. Graphs are shown for (A) E542E (wild-type), (B) E542K (mutant), (C) E545E (wild-type), (D) E545K (mutant), (E) H1047H (wild-type) and (F) H1047R (mutant). PIK3CA, phosphatidylinositol-4,5-bisphosphate 3-kinase catalytic $\alpha$ subunit.

\section{Results}

Clinical and histopathological characteristics. The mean age of the patient population was $50.26 \pm 11.36$ years. Histopathological analysis revealed that the majority of the patients presented with grade 2 and stage 2 breast cancer, and the patient prognosis was ascertained based on 12 parameters, as described earlier ( $\geq 8$ parameters indicated poor, and $<8$ parameters indicated good prognosis; Table I). Ductal carcinoma was observed in $95.76 \%$ of the patients, whereas only $4.2 \%$ of the patients presented with lobular carcinoma. Based on ER, PR and HER2 expression levels, it was determined that $62.7 \%$ of the cases exhibited high ER expression and $50 \%$ exhibited low PR expression, while $74.6 \%$ of patients were HER 2 . In the patient cohort, $45 \%$ of cases were $\mathrm{ER}^{+} / \mathrm{PR}^{+}$, while $64.4 \%$ were ER $/ \mathrm{PR}^{-}$. The lowest frequency of two marker positive expression was seen in the $\mathrm{PR}^{+} / \mathrm{HER} 2^{+}$and $\mathrm{ER}^{+} / \mathrm{HER} 2^{+}$groups at 7.6 and $9.3 \%$ respectively. When the patients were classified into the different marker groups based on ER, PR and HER2 expression, the majority of the cases were assigned to the $\mathrm{ER}^{+} / \mathrm{PR}^{+}$and HER2 group (39\%), with the $\mathrm{ER} / \mathrm{PR}^{+}$and $\mathrm{HER} 2^{+}$group exhibiting the lowest frequency $(1.7 \%)$.

PIK3CA helical and kinase domain mutations. Three mutations, namely E542K and E545K within exon 9, and H1047R within exon 20, were observed in 25 of the 118 patients (21.2\%; Table I). Among these 25 patients, 3 carried the E542K helical domain mutation, while 4 carried the E545K helical domain mutation (data not shown). The remaining 18 patients carried the H1047R mutation of the kinase domain (Table I). This indicated that the frequency of the kinase domain mutation was significantly greater when compared with the helical domain mutation ( $\mathrm{P}=0.019$; data not shown). The patients were then classified into two groups based on good prognosis (53\%) or poor prognosis $(46.6 \%)$. Accordingly, it was observed that the PIK3CA mutation was significantly associated with poor prognosis $(\mathrm{P}=0.023)$. Furthermore, once the patient cohort was stratified based on the expression of the three receptors (ER, PR and HER2), PIK3CA mutations were associated with the $\mathrm{ER}^{+} / \mathrm{PR}^{+}$group of tumors in contrast to the $\mathrm{ER}^{-} / \mathrm{PR}^{-}$group $(\mathrm{P}=0.021)$.

The helical and kinase domain mutations were independently analyzed to determine the association with histopathological and prognostic indicators. This analysis revealed that there was no independent association of the indicators, whereas the PIK3CA mutation was overall associated with a poor prognosis. A significant association was identified between the $\mathrm{ER}^{+} / \mathrm{PR}^{+}$subgroup and the H1047R kinase domain mutation of PIK3CA ( $\mathrm{P}=0.038)$; however, no association with the helical domain mutations was identified (Table II).

\section{Discussion}

RTK signaling induces the activation of Ras/mitogen-activated protein kinase and the Ras/PI3K/protein kinase B (AKT) signaling pathways, resulting in increased proliferation, survival and metastasis of cancer cells. Somatic mutations in RTKs, Ras, B-Raf, PI3K and AKT are commonly observed in various cancer types $(25,26)$. Thus, research has focused on the genetic alterations in the genes involved in these pathways for use in targeted therapy. Samuels et al (3) identified 


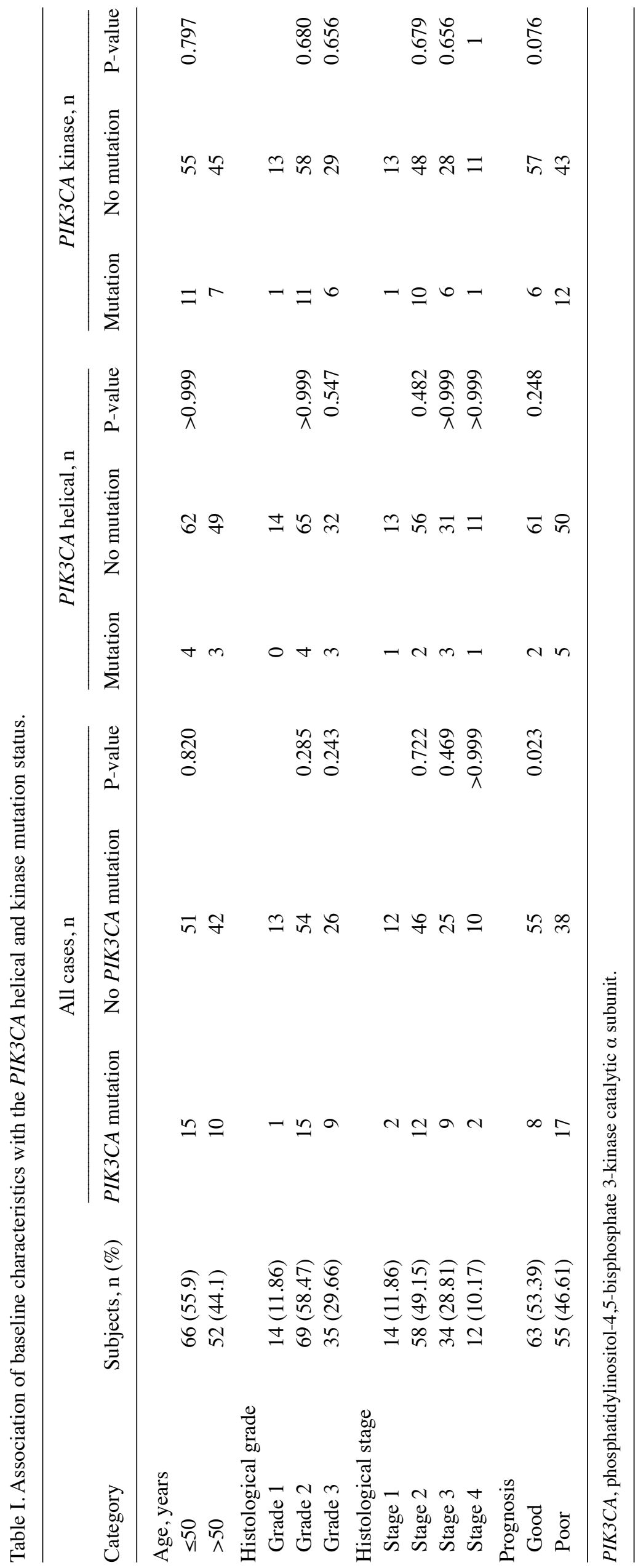


Table II. Hormone receptor subsets, and the PIK3CA helical and kinase mutation status.

\begin{tabular}{|c|c|c|c|c|c|c|c|c|c|}
\hline \multirow[b]{2}{*}{ Category } & \multicolumn{3}{|c|}{ All cases, $\mathrm{n}$} & \multicolumn{3}{|c|}{ PIK3CA helical, $\mathrm{n}$} & \multicolumn{3}{|c|}{ PIK3CA kinase, $\mathrm{n}$} \\
\hline & $\begin{array}{l}\text { PIK3CA } \\
\text { mutation }\end{array}$ & $\begin{array}{c}\text { No PIK3CA } \\
\text { mutation }\end{array}$ & P-value & Mutation & $\begin{array}{c}\text { No } \\
\text { mutation }\end{array}$ & P-value & Mutation & $\begin{array}{c}\text { No } \\
\text { mutation }\end{array}$ & P-value \\
\hline $\mathrm{ER}^{+}$ & 17 & 57 & & 4 & 70 & & 13 & 61 & \\
\hline $\mathrm{ER}^{-}$ & 8 & 36 & 0.644 & 3 & 41 & 0.711 & 5 & 39 & 0.435 \\
\hline $\mathrm{PR}^{+}$ & 14 & 45 & & 4 & 55 & & 10 & 49 & \\
\hline $\mathrm{PR}^{-}$ & 11 & 48 & 0.652 & 2 & 57 & 0.679 & 8 & 51 & 0.608 \\
\hline $\mathrm{HER}^{+}{ }^{+}$ & 6 & 24 & & 3 & 27 & & 3 & 27 & \\
\hline HER2- & 19 & 69 & $>0.999$ & 4 & 84 & 0.368 & 15 & 73 & 0.556 \\
\hline ER-PR- & 6 & 70 & & 2 & 74 & & 4 & 72 & \\
\hline $\mathrm{ER}^{+} \mathrm{PR}^{+}$ & 12 & 41 & 0.021 & 3 & 50 & 0.401 & 9 & 44 & 0.038 \\
\hline $\mathrm{ER}^{-\mathrm{PR}^{+}}$ & 6 & 32 & 0.210 & 2 & 36 & 0.599 & 4 & 34 & 0.437 \\
\hline $\mathrm{ER}^{+} \mathrm{PR}^{-}$ & 5 & 16 & 0.056 & 1 & 20 & 0.523 & 4 & 17 & 0.064 \\
\hline ER-HER2- & 5 & 20 & & 1 & 24 & & 4 & 21 & \\
\hline ER $^{+} \mathrm{HER}^{+}{ }^{+}$ & 3 & 8 & 0.678 & 1 & 10 & 0.523 & 2 & 9 & $>0.999$ \\
\hline ER-HER2 $^{+}$ & 3 & 16 & $>0.999$ & 2 & 17 & 0.569 & 1 & 18 & 0.370 \\
\hline ER ${ }^{+}$HER2- & 14 & 49 & $>0.999$ & 3 & 60 & $>0.999$ & 11 & 52 & $>0.999$ \\
\hline PR'HER2- & 7 & 31 & & 2 & 36 & & 5 & 33 & \\
\hline $\mathrm{PR}^{+} \mathrm{HER}^{+}{ }^{+}$ & 2 & 7 & $>0.999$ & 2 & 7 & 0.160 & 0 & 9 & 0.566 \\
\hline PR-HER2+ ${ }^{+}$ & 4 & 17 & $>0.999$ & 1 & 20 & $>0.999$ & 4 & 17 & 0.707 \\
\hline $\mathrm{PR}^{+} \mathrm{HER}^{2}-$ & 12 & 38 & 0.607 & 2 & 48 & $>0.999$ & 10 & 40 & 0.568 \\
\hline ER-PR-HER2- & 4 & 17 & & 1 & 20 & & 3 & 18 & \\
\hline ER-PR ${ }^{+} \mathrm{HER}^{-}$ & 1 & 3 & $>0.999$ & 0 & 4 & $>0.999$ & 1 & 3 & 0.526 \\
\hline $\mathrm{ER}^{+} \mathrm{PR}^{+} \mathrm{HER} 2^{-}$ & 11 & 35 & 0.760 & 2 & 44 & $>0.999$ & 9 & 37 & 0.739 \\
\hline $\mathrm{ER}^{+} \mathrm{PR}^{+} \mathrm{HER} 2^{+}$ & 1 & 6 & $>0.999$ & 1 & 6 & 0.444 & 0 & 7 & 0.551 \\
\hline ER $^{+} \mathrm{PR}^{-}{ }^{-H E R} 2^{+}$ & 2 & 2 & 0.234 & 0 & 4 & $>0.999$ & 2 & 2 & 0.166 \\
\hline ER+PR-HER2- & 3 & 14 & $>0.999$ & 1 & 16 & $>0.999$ & 2 & 15 & $>0.999$ \\
\hline ER-PR-HER2+ & 2 & 15 & 0.672 & 1 & 16 & $>0.999$ & 1 & 16 & 0.613 \\
\hline ER-PR ${ }^{+} \mathrm{HER} 2^{+}$ & 1 & 1 & 0.395 & 1 & 1 & 0.170 & 0 & 2 & $>0.999$ \\
\hline
\end{tabular}

Fisher's exact test was used to calculate the statistical significance. PIK3CA, phosphatidylinositol-4,5-bisphosphate 3-kinase catalytic $\alpha$ subunit; ER, estrogen receptor; PR, progesterone receptor; HER2, human epidermal growth factor receptor 2.

PIK3CA gene mutations in a small study cohort and suggested that these mutations may be involved in the development of cancer. These mutations were primarily concentrated in the helical, kinase and p85 binding domains. Subsequent studies in different population groups revealed that the frequency of these mutations ranged between 21.3 and $34.7 \%(2,16)$. A study by Karakas et al (27) conducted on a central Saudi Arabian population reported the frequency of these mutations to be $26 \%$. The present study indicated a frequency of $21.2 \%$ for these mutations in breast cancer patients in the eastern province of Saudi Arabia, which was comparable with the findings of Karakas et al (27). Furthermore, the current study revealed that the frequency of mutations in exons 9 and 20 was 5.9 and $15.25 \%$, respectively. However, none of the patients included in the current study presented with these two mutations simultaneously. These results are in line with previously reported studies in other population groups $(2,16,28,29)$.

According to the current study data, it can be suggested that PIK3CA mutations are observed in similar percentages worldwide. However, the higher frequency of kinase domain mutations in the present study, particularly H1047R, suggested the need for targeted therapy to inhibit PIK3CA activity via the H1047R mutation. A number of studies have investigated the association between these mutations and clinicopathological parameters, including hormone receptor expression, stage, grade, metastases and prognosis of breast cancer (4-8). A previous meta-analysis comprising 32 different studies reported that ER and PR expression levels were significantly correlated with $P I K 3 C A$ mutations $(\mathrm{P}<0.00001)$ (4). HER2-overexpressing breast tumors were correlated with a high $P I K 3 C A$ mutation rate (5). A study by Li et al (6) confirmed that there was a correlation between PIK3CA mutations, and the ER and PR overexpression in large tumors. The present study results were in line with these aforementioned studies, and reinforced the correlation of ER and PR overexpression with the high frequency of PIK3CA mutations $(\mathrm{P}=0.021)$. However, ER and PR overexpression were significantly correlated with the kinase domain mutation (H1047R; 


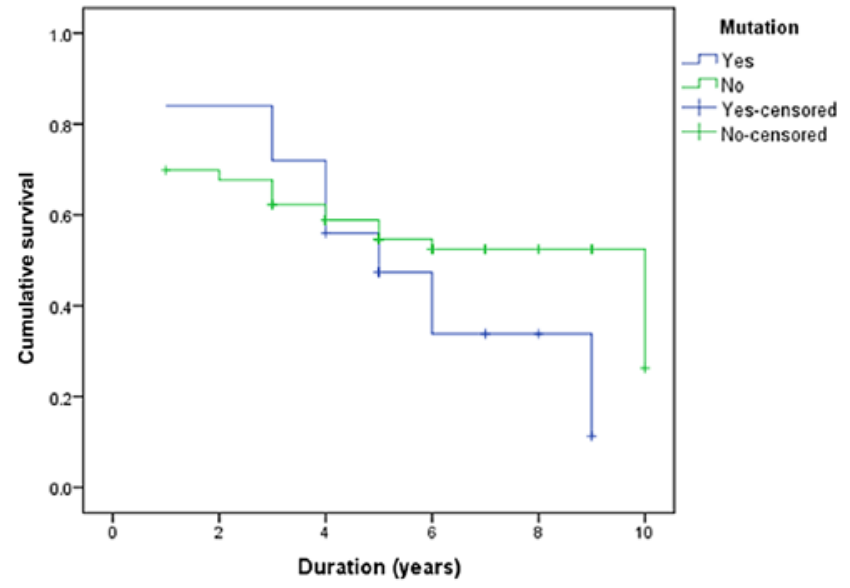

Figure 2. Kaplan-Meier curve comparing the survival of the patients with and without $P I K 3 C A$ mutation. Censored refers to cases with incomplete survival data or loss to follow up. PIK3CA, phosphatidylinositol-4,5-bisphosphate 3-kinase catalytic $\alpha$ subunit.

$\mathrm{P}=0.038)$ rather than the helical domain mutations $(\mathrm{P}=0.401)$. It has also been reported that $\mathrm{ER}^{+}$tumors were associated with a higher frequency of $P I K 3 C A$ mutations and that ER could be activated in the absence of estrogen, which causes tamoxifen resistance (7). Furthermore, a study by Ellis et al (8) demonstrated that tumors with PIK3CA mutations did not respond to neoadjuvant endocrine therapy as compared with tumors without PIK3CA mutations.

Several retrospective and prospective studies have evaluated the prognostic and predictive value of PIK3CA mutations in breast cancer tumors. However, these studies reached contradictory conclusions, with certain studies demonstrating the association of PIK3CA mutations with poor survival $(9,10)$, while others indicating that $P I K 3 C A$ mutations was associated with a better survival rate $(11,12)$. In addition, a study by Barbareschi et al (13) reported that only exon 9 mutations were associated with poor survival. Furthermore, a meta-analysis comprising seven studies revealed that $P I K 3 C A$ mutations have no prognostic impact (4). In this previous meta-analysis, the prognosis was defined by overall survival and progression-free survival. Similarly, in the present study, the PIK3CA mutations did not yield a significant impact on overall survival $(\mathrm{P}=0.248$; Fig. 2$)$. However, sub-data analysis based on 12 parameters indicated that the PIK3CA mutations within exons 9 and 20 were associated with poor prognosis $(\mathrm{P}=0.023)$. Several studies revealed variation in the significant correlation between PIK3CA mutation and overall survival (9-13), while the data of the present study indicated no significant impact. The possible reasons may include the different exonic mutations that may impact different mechanisms, the breast cancer-specific effect of PIK $3 C A$ mutations (4), and the impact of treatment, which greatly varies subsequent to recurrence (17).

Recent clinical and experimental studies suggested that PI3K pathway activation may negatively affect the response of breast cancer patients to trastuzumab, a monoclonal therapy drug (2). This conclusion emphasized the need to assess the PIK3CA mutation status following trastuzumab therapy for breast cancer in order to predict disease progression $(14,15)$.
Currently, only one drug that targets the PI3K pathway is available for breast cancer treatment, namely everolimus, which is an mTOR inhibitor. PIK3CA mutations may provide an opportunity to develop novel drugs that target altered $P I K 3 C A$, or combination therapy based on the current regimen, which may yield the maximum effect on breast tumors. Therefore, determining the PIK3CA mutation status has valuable clinical relevance in terms of disease prediction and prognosis.

Different detection methods exist to identify mutations in a gene. The standard method is direct sequencing, which identifies existing and de novo mutations, unlike amplification-refractory mutation system PCR or quantitative PCR-based methods (30). All these methods have their respective sensitivity in detecting the mutation status. The vast majority of studies have employed Sanger sequencing to determine PIK3CA mutations (4). Based on the meta-analysis conducted by Pang et al (4) on PIK3CA mutations in breast cancer, 18 out of 26 studies determined the PIK3CA sequence by Sanger sequencing. Another study by Papaxoinis et al (21) reported a good concordance between direct sequencing and next-generation sequencing methods. The present study employed direct sequencing and a TaqMan mutation detection assay by CAST PCR. Initially, all the samples were subjected to direct sequencing, followed by further validation of samples with PIK3CA mutations using CAST PCR. All PIK3CA mutation positive samples and $10 \%$ of the $P I K 3 C A$ mutation negative samples assessed using CAST PCR recorded 100\% concordance with direct sequencing results. Thus, both Sanger sequencing and CAST PCR assays can be used to detect PIK3CA mutations. However, CAST PCR may be a preferred method due to high detection sensitivity, low cost and time efficiency.

In conclusion, the present study emphasized that $P I K 3 C A$ mutations may serve as important biomarkers for breast cancer classification and for targeted therapies using PIK3CA inhibitors.

\section{Acknowledgements}

The authors would like to thank Mr. Geoffrey James Tam Moro, Mr. Florentino Mata Jr and Mr. Mohammed H. Al-Shamlan (Imam Abdulrahman Bin Faisal University) for their technical support.

\section{Funding}

The current study was supported by The Deanship of Scientific Research, Imam Abdulrahman Bin Faisal University (grant nos. 2014048 and 2016-090-IRMC).

\section{Availability of data and materials}

The datasets used and/or analyzed during the current study are available from the corresponding author on reasonable request.

\section{Authors' contributions}

CV and AMAA conceived and designed the study. AMAA, AAl, AAh, MSA, NFA and HAW collected the samples and provided the clinical data. CV, CC and SC conducted experiments. CV 
and NJ performed statistical analysis. CV drafted the manuscript. AAZ and AKAA conceived, designed the study and revised the manuscript for important intellectual content. All authors have read and approved the final manuscript.

\section{Ethics approval and consent to participate}

The current study was approved by the Institutional Review Board of Imam Abdulrahman Bin Faisal University, Dammam, Saudi Arabia. Written informed consent was obtained from the patients.

\section{Patient consent for publication}

Not applicable.

\section{Competing interests}

The authors declare that they have no competing interests.

\section{References}

1. Ghoncheh M, Pournamdar Z and Salehiniya H: Incidence and mortality and epidemiology of breast cancer in the world. Asian Pac J Cancer Prev 17: 43-46, 2016.

2. Cizkova M, Dujaric ME, Lehmann-Che J, Scott V, Tembo O, Asselain B, Pierga JY, Marty M, de Cremoux P, Spyratos F and Bieche I: Outcome impact of PIK3CA mutations in HER2-positive breast cancer patients treated with trastuzumab. Br J Cancer 108: 1807-1809, 2013.

3. Samuels Y, Wang Z, Bardelli A, Silliman N, Ptak J, Szabo S, Yan H, Gazdar A, Powell SM, Riggins GJ, et al: High frequency of mutations of the PIK3CA gene in human cancers. Science 304 554, 2004.

4. Pang B, Cheng S, Sun SP, An C, Liu ZY, Feng X and Liu GJ: Prognostic role of PIK3CA mutations and their association with hormone receptor expression in breast cancer: A meta-analysis. Sci Rep 4: 6255, 2014.

5. Stemke-Hale K, Gonzalez-Angulo AM, Lluch A, Neve RM, Kuo WL, Davies M, Carey M, Hu Z, Guan Y, Sahin A, et al: An integrative genomic and proteomic analysis of PIK3CA, PTEN, and AKT mutations in breast cancer. Cancer Res 68: 6084-6091, 2008.

6. Li SY, Rong M, Grieu F and Iacopetta B: PIK3CA mutations in breast cancer are associated with poor outcome. Breast Cancer Res Treat 96: 91-95, 2006.

7. Campbell RA, Bhat-Nakshatri P, Patel NM, Constantinidou D, Ali S and Nakshatri H: Phosphatidylinositol 3-kinase/AKTmediated activation of estrogen receptor alpha: A new model for anti-estrogen resistance. J Biol Chem 276: 9817-9824, 2001

8. Ellis MJ, Lin L, Crowder R, Tao Y, Hoog J, Snider J, Davies S, DeSchryver K, Evans DB, Steinseifer J, et al Phosphatidyl-inositol-3-kinase alpha catalytic subunit mutation and response to neoadjuvant endocrine therapy for estrogen receptor positive breast cancer. Breast Cancer Res Treat 119: 379-390, 2010.

9. Lai YL, Mau BL, Cheng WH, Chen HM, Chiu HH and Tzen CY: PIK3CA exon 20 mutation is independently associated with a poor prognosis in breast cancer patients. Ann Surg Oncol 15 1064-1069, 2008.

10. Lerma E, Catasus L, Gallardo A, Peiro G, Alonso C, Aranda I, Barnadas A and Prat J: Exon 20 PIK3CA mutations decreases survival in aggressive (HER-2 positive) breast carcinomas. Virchows Arch 453: 133-139, 2008.

11. Maruyama N, Miyoshi Y, Taguchi T, Tamaki Y, Monden M and Noguchi S: Clinicopathologic analysis of breast cancers with PIK3CA mutations in Japanese women. Clin Cancer Res 13: 408-414, 2007

12. Pérez-Tenorio G, Alkhori L, Olsson B, Waltersson MA, Nordenskjöld B, Rutqvist LE, Skoog L and Stål O: PIK3CA mutations and PTEN loss correlate with similar prognostic factors and are not mutually exclusive in breast cancer. Clin Cancer Res 13: 3577-3584, 2007.
13. Barbareschi M, Buttitta F, Felicioni L, Cotrupi S, Barassi F, Del Grammastro M, Ferro A, Dalla Palma P, Galligioni E and Marchetti A: Different prognostic roles of mutations in the helical and kinase domains of the PIK3CA gene in breast carcinomas. Clin Cancer Res 13: 6064-6069, 2007.

14. Ligresti G, Militello L, Steelman LS, Cavallaro A, Basile F, Nicoletti F, Stivala F, McCubrey JA and Libra M: PIK3CA mutations in human solid tumors: Role in sensitivity to various therapeutic approaches. Cell Cycle 8: 1352-1358, 2009.

15. Jensen JD, Knoop A, Laenkholm AV, Grauslund M, Jensen MB, Santoni-Rugiu E, Andersson M and Ewertz M: PIK3CA mutations, PTEN, and pHER2 expression and impact on outcome in HER2-positive early-stage breast cancer patients treated with adjuvant chemotherapy and trastuzumab. Ann Oncol 23: 2034-2042, 2012.

16. Hashimoto K, Tsuda H, Koizumi F, Shimizu C, Yonemori K, Ando M, Kodaira M, Yunokawa M, Fujiwara Y and Tamura K: Activated PI3K/AKT and MAPK pathways are potential good prognostic markers in node-positive, triple-negative breast cancer. Ann Oncol 25: 1973-1979, 2014.

17. Mukohara T: PI3K mutations in breast cancer: Prognostic and therapeutic implications. Breast Cancer (Dove Med Press) 7: 111-123, 2015.

18. Saal LH, Holm K, Maurer M, Memeo L, Su T, Wang X, Yu JS, Malmström PO, Mansukhani M, Enoksson J, et al: PIK3CA mutations correlate with hormone receptors, node metastasis, and ERBB2, and are mutually exclusive with PTEN loss in human breast carcinoma. Cancer Res 65: 2554-2559, 2005.

19. Mankoo PK, Sukumar S and Karchin R: PIK3CA somatic mutations in breast cancer: Mechanistic insights from Langevin dynamics simulations. Proteins 75: 499-508, 2009.

20. Zhao JJ, Liu Z, Wang L, Shin E, Loda MF and Roberts TM: The oncogenic properties of mutant p110alpha and p110beta phosphatidylinositol 3-kinases in human mammary epithelial cells. Proc Natl Acad Sci USA 102: 18443-18448, 2005.

21. Papaxoinis G, Kotoula V, Alexopoulou Z, Kalogeras KT, Zagouri F, Timotheadou E, Gogas H, Pentheroudakis G, Christodoulou C, Koutras A, et al: Significance of PIK3CA mutations in patients with early breast cancer treated with adjuvant chemotherapy: A Hellenic Cooperative Oncology Group (HeCOG) study. PLoS One 10: e0140293, 2015.

22. Cancer Incidence report Saudi Arabia 2014. Available from: http://www.chs.gov.sa/En/HealthRecords/CancerRegistry/ Pages/CancerRegistryRecords.aspx 2014.

23. Zhang BN, Cao XC, Chen JY, Chen J, Fu L, Hu XC, Jiang ZF, Li HY, Liao N, Liu DG, et al: Guidelines on the diagnosis and treatment of breast cancer (2011 edition). Gland Surg 1: 39-61, 2012.

24. Al-Amri AM, Vatte C, Cyrus C, Chathoth S, Hashim TM, Mohamed YS, Al Ali R, Alsaid A and Al Ali A: Novel mutations of PIK3CA gene in head and neck squamous cell carcinoma. Cancer Biomark 16: 377-383, 2016.

25. Regad T: Targeting RTK signaling pathways in cancer. Cancers (Basel) 7: 1758-1784, 2015.

26. Vatte C, Al Amri AM, Cyrus C, Chathoth S, Acharya S, Hashim TM, Al Ali Z, Alshreadah ST, Alsayyah A and Al-Ali AK: Tyrosine kinase domain mutations of EGFR gene in head and neck squamous cell carcinoma. Onco Targets Ther 10: 1527-1533, 2017.

27. Karakas B, Colak D, Kaya N, Ghebeh H, Al-Qasem A, Hendrayani F, Toulimat M, Al-Tweigeri T, Park BH and Aboussekhra A: Prevalence of PIK3CA mutations and the SNP rs17849079 in Arab breast cancer patients. Cancer Biol Ther 14: 888-896, 2013

28. Beelen K, Opdam M, Severson TM, Koornstra RH, Vincent AD, Wesseling J, Muris JJ, Berns EM, Vermorken JB, van Diest PJ and Linn SC: PIK3CA mutations, phosphatase and tensin homolog, human epidermal growth factor receptor 2, and insulin-like growth factor 1 receptor and adjuvant tamoxifen resistance in postmenopausal breast cancer patients. Breast Cancer Res 16: $\mathrm{R} 13,2014$.

29. Abramson VG, Cooper Lloyd M, Ballinger T, Sanders ME, Du L, Lai D, Su Z, Mayer I, Levy M, LaFrance DR, et al: Characterization of breast cancers with PI3K mutations in an academic practice setting using SNaPshot profiling. Breast Cancer Res Treat 145: 389-399, 2014.

30. Diekstra A, Bosgoed E, Rikken A, van Lier B, Kamsteeg EJ, Tychon M, Derks RC, van Soest RA, Mensenkamp AR, Scheffer H, et al: Translating sanger-based routine DNA diagnostics into generic massive parallel ion semiconductor sequencing. Clin Chem 61: 154-162, 2015.

This work is licensed under a Creative Commons Attribution 4.0 International (CC BY 4.0) License. 